\title{
Formação em Psicologia: Discursos e Saberes sobre Experimentações de Gênero
}

Training in Psychology: Discourses and Knowledge about Gender trials

Formación en Psicología: Discursos y Saberes sobre Experimentaciones de Género
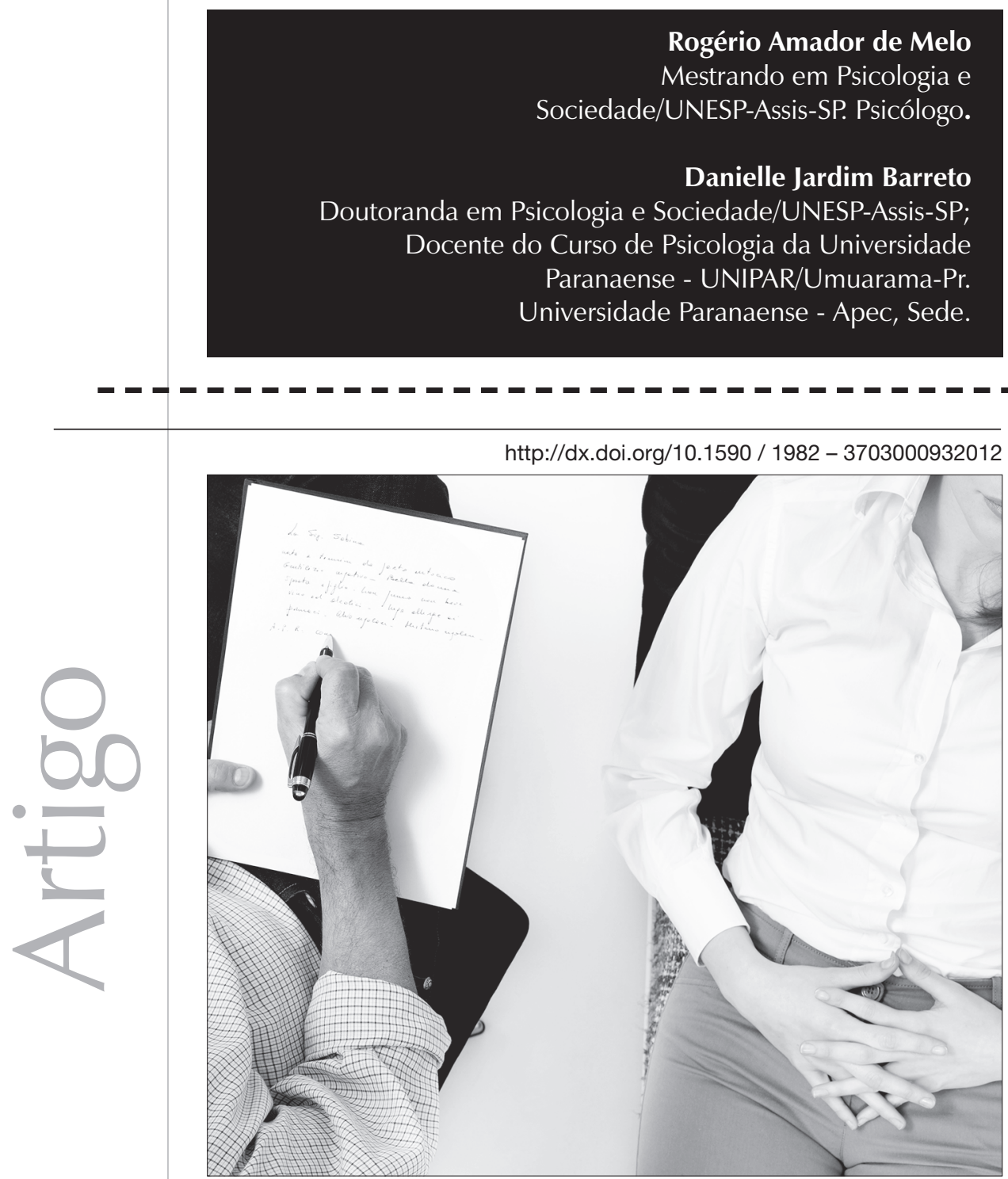
Resumo: Contemporaneamente, diversas discussões e problematizações a respeito às "novas configurações" de gênero vem produzindo desafios e embates teóricos até então sutilmente abordados pelos meios de comunicação e na academia como processos psicopatológicos, exigindo assim novos olhares e concepções sobre as questões de gênero, do agenciamento das relações que engendram a diversidade sexual e as identidades e sexualidades dissidentes. Partindo desses pressupostos, o presente artigo propõe cartografar às produções de saberes no campo da Psicologia, nos enunciados produzidos pelos sujeitos neste território subjetivo, além dos efeitos dessa produção discursiva instituída na formação dos acadêmicos inseridos neste curso.

Palavras-chave: Formação do psicólogo. Gênero. Identidade de Gênero. Sexualidade.

Abstract: Contemporaneously, several discussions and concerns about the "new settings" gender has produced challenges and theoretical debates subtly addressed so far by the media and academia as psychopathological processes, thus requiring new approaches and conceptions about gender issues, the agency relationships that engender diversity and sexual identities and sexualities dissidents. Based on these assumptions, this paper proposes to map out the production of knowledge in the field of psychology, in the utterances produced by subjects in the subjective territory, beyond the effects of this discursive production established in the training of students entered this course.

Keywords: Psychologist education. Gender. Gender identity. Sexuality.

Resumen: En la misma época, varias discusiones y preocupaciones acerca de la "nueva configuración" de género ha producido problemas y debates teóricos sutilmente dirigidas hasta ahora por los medios de comunicación y los círculos académicos como los procesos psicopatológicos, por lo que requiere nuevos enfoques y concepciones sobre las cuestiones de género, la agencia relaciones que generan la diversidad y las identidades sexuales y de los disidentes sexualidades. Partiendo de estas premisas, el presente trabajo se propone un mapa de la producción de conocimiento en el campo de la psicología, en los enunciados producidos por los sujetos en el territorio subjetivo, más allá de los efectos de esta producción discursiva establecida en la formación de los estudiantes entró en este curso.

Palabras - clave: Formación del psicólogo.Género. Identidad de género. Sexualidad.

Considerando que os discursos e saberes produzidos na formação em Psicologia estão inseridos no campo das ciências humanas em suas diversificações de conhecimento, sendo este entendido como o campo da ciência que tem por foco de intervenção e produção de saberes o território subjetivo da existência humana, faz-se pertinente visualizar o engendramento dos enunciados que são articulados nesse contexto.

Os saberes produzidos sobre e para esse sujeito não estão desconectados de um contexto socioeconômico cultural, permitindo que nos indaguemos sobre a produção de quais verdades sobre o que somos/estamos estão sendo enunciadas nos cursos de formação em Psicologia após a implementação das Diretrizes Curriculares Nacionais.

Como já explicitado, a produção de saber não está desconectada da história, a formação em Psicologia enquanto campo de saber dito autônomo advém da racionalização engendrada na modernidade por meio do projeto de afastamento da Filosofia e aproximação das ciências médicas positivistas. Essa aproximação permitiu a construção de saberes sobre o homem fortemente vinculado às dicotomias saúde/doença, indivíduo/sociedade, 
à identificação psicodiagnóstica e cura das ditas anormalidades nos modos de viver contemporâneos. Essa formação psi pautada na Medicina produziu ao longo da história práticas e saberes estigmatizantes, desconectados do contexto histórico e da realidade social.

Desse modo, a problematização da pesquisa, resultando neste artigo, entende as práticas discursivas da Psicologia como técnicas de subjetivação, por isso a necessidade de visualização das produções de saberes/verdades acerca do sujeito que é atravessado pelas práticas psi, que até então (antes das diretrizes curriculares) enaltecia a formação clínica individualizada, entendendo o homem como um ser em constante busca de si mesmo.

Em virtude dessas considerações, o objetivo que se enuncia nesta pesquisa de trabalho de conclusão de curso foi cartografar quais discursos, enquanto produção de saberes/verdades, estão sendo produzidos nos cursos de Psicologia acerca da práxis a respeito da diferença sexual, identidades e sexualidades dissidentes ${ }^{1}$, além dos efeitos produzidos nos graduandos desde o processo de entrada no curso e sua respectiva finalização, problematizando a produção de saber na formação em Psicologia a partir da implementação das diretrizes curriculares e das especificidades de disciplinas que abordem essa temática. Para tanto, a metodologia utilizada foi de pesquisa in loco realizada nos meses de agosto e setembro do ano de 2011, em uma universidade pública e outra privada do estado do Paraná, com uma amostra de 16 acadêmicos do primeiro e último ano do curso de Psicologia, por meio de uma entrevista semiestrutura abordando os temas de diferença sexual, identidades e sexualidades dissidentes.

Sendo que a nosso pensar se fez pertinente cartografar territórios subjetivos distintos, seja no tocante à produção de saberes/verdades, bem como das relações que se configuram nesses locais, por isso a decisão de realizar a pesquisa em instituição pública e privada, onde o resultado acabou nos mostrando que não somente as relações instituídas ali agenciam saberes/verdades, mas também os agen- ciamentos dos enunciados produzidos atravessam e engendram os possíveis campos de experimentação do corpo e do desejo.

\section{Começando nosso mapa: sobre os discursos e suas facetas de análise}

Ao pensarmos na produção de discurso da formação em Psicologia para contemporaneidade, temos que trazer à discussão as produções de saberes agenciados na formação acadêmica e nas práticas produzidas durante esta.

Essa problematização se faz necessária devido ao percurso que a ciência psicológica passou e está passando, em contraste com as demandas advindas das relações estabelecidas no cotidiano de uma sociedade globalizada. Assim, dentro dessa espacialidade, a formação em Psicologia até então ainda em uma visão tradicional, conforme Guareschi e Dhein (2009, p. 64) “(...) não tecia até muito pouco tempo relações com acontecimentos ou fatos que levassem a pensar a cultura como constituinte do sujeito e muito menos a cultura como uma dimensão simbólica como práticas de significação e com suas implicações políticas".

Dessa forma, a compreensão da constituinte do sujeito acaba percebida distante das implicações políticas, de saberes e de práticas; posteriormente reproduzindo e reforçando teorias/saberes de naturalização e interioridade a respeito desse sujeito (Guareschi \& Dhein, 2009).

Sendo o homem objeto de produção e intervenção, é preciso fundir saberes sobre este por meio da miscigenação defendida por Serres (1993), para a compreensão da complexidade e produção dos saberes da completude do humano. Para Ceccin e Pinheiro (2005), é preciso visualizar a mestiçagem dos saberes como "(...) duas populações, de um lado as ciências sociais ou naturais, donde a saúde; de outro as humanidades, donde a arte, a alteridade, as sensibilidades e os afetos" (Ceccin \& Pinheiro, 2005, p.31). 
Assim, por não existir somente uma Psicologia pautada em uma interioridade e naturalização como constituinte do sujeito, mas que a partir de outras contribuições teóricas percebe-se e permite-se pensar em outras possibilidades de produção de subjetividade e até mesmo no que infere na sua constituição. Pensa-se esse sujeito não mais de forma natural e essencializado, mas em uma rede na qual a cultura, os contextos sociais e históricos agenciam práticas de significações os quais o constituem.

Segundo Foucault (1996) torna-se necessário analisar os discursos em suas condições, em seus jogos e em seus efeitos, pois os discursos não são de ordem natural, mas sim permeados ou pode-se assim dizer que são agenciados dentro do contexto social de uma forma organizada, selecionada, redistribuída e controlada, tendo um objetivo específico e não aleatório. Desse modo, o discurso se configura e se dá na ordem das leis, em um território de subjetivação que é constantemente inferido pelas interdições das relações de poder e de desejo. Convém ressaltar então que: “(...) o discurso não é simplesmente aquilo que traduz as lutas ou os sistemas de dominação, mas aquilo por que, pelo que se luta, o poder do qual nos queremos apoderar" (Foucault, 1996, p. 10).

É importante ressaltar que esse desejo de apoderar-se do poder ou a vontade de verdade, em seu cerne e na sua rede rizomática institucional é o que desempenha de certa forma a coação sobre os demais discursos. É relevante mencionar que essa processualidade é epistemológica, tendo suas configurações e processos estabelecidos em cada momento de maneira diferente, mas com os mesmos propósitos.

Os discursos produzem verdades, verdade sobre o outro e sobre as possibilidades de vir a ser. As verdades produzem territórios de subjetivação e objetivação dos sujeitos. Como se pode notar, o agenciamento de verdades são delimitados e controlados a partir do discurso, por meio de procedimentos tanto internos quanto externos, sendo o primeiro na ordem de efetuar sobre si mesmo o controle na dimensão do acaso e do acon- tecimento; enquanto o segundo é na ordem de redes de exclusão configuradas no campo do desejo e do poder. Nesse sentido é possível dizer que a produção de verdades sempre se dá, de acordo com o autor supracitado, "(...) no espaço de uma exterioridade selvagem; mas não nos encontramos no verdadeiro senão obedecendo às regras de uma 'política' discursiva que devemos reativar em cada um de nossos discursos" (Foucault, 1996, p. 35).

É preciso insistir também no fato de que tal controle na produção do discurso no âmbito da formação em Psicologia tem seu eixo no estabelecimento da disciplina, sendo esta a que firma através de regras específicas os extremos territoriais do saber e da sua reatualização. Desse modo, se queremos adentrar as relações estabelecidas nesse campo institucional e subjetivado é necessário interromper temporariamente o poder do significante, problematizar a vontade de verdade e devolver ao discurso sua característica de acontecimento.

\section{"Existir é resistir": Processos de subjetivação e produção de di- ferença nas experimentações da sexualidade}

No que diz respeito às novas possibilidades de existência e de entendimento em relação ao sujeito, seu desejo e sexualidade, pondera Michel Foucault (1984) sobre o atravessamento de saberes/verdades epistemológicas que "determinam" e estabelecem campos subjetivos de existência e de experimentação do próprio corpo e do desejo. Uma delimitação de possibilidades que são agenciadas por códigos simbólicos e discursivos sobre o desejo, a sexualidade e sobre o próprio sujeito, dentro de padrões hegemônicos e binários das práticas de poder contextualizadas e reafirmadas em uma descontinuidade de discursos históricos.

Correspondendo, segundo o autor, a quatro dispositivos que emergem com força nesse contexto sobre os modos de subjetivação: 
“(...) natureza do ato sexual, fidelidade monogâmica, relações homossexuais, castidade (...)" (Foucault, 1984, p. 17). Para Foucault então, o sujeito e a subjetividade são agenciados e produzidos em um processo de subjetivação, no qual não se pode dizer que exista uma constituição moral do sujeito sem modos de subjetivação.

Assim, é apresentado no campo relacional dos saberes problematizações que por meio das suas afetações têm, de certo modo, desconstruído ou tentado desconstruir "verdades" subjetivas sobre/para o sujeito, partindo das questões mais pertinentes durante toda a história humana, que é a questão da sexualidade. Dentro de uma visão foucaultiana, a subjetividade envolve agenciamentos rizomáticos de redes de afetações, a subjetividade "tem a ver com o tempo e com o corpo" (Cardoso, 2005, p. 345). Nesse sentido, pensar o sujeito e sua subjetividade é problematizar, articular discussões a respeito da temporalidade epistemológica que define esse corpo e seu possível território de desejo e existência.

Dessa forma, sujeito, corpo e produção de saberes/discursos agenciam modos de subjetivação que capturam o entendimento de si e do outro, outorgando desejos e territórios subjetivos de sexualidade cerceados pelas relações de poder e o sujeito ético/moral; assim, “(...) a subjetividade deve ser entendida como parte integrante desta ordem maquinaria moderna correlativa às várias práticas sociais, sejam as de ordem discursiva, sejam aquelas presentes no campo dos dispositivos, sejam as que se dão pelos processos de subjetivação" (Soler, 2008, p. 573). Tal articulação se faz necessária pela constante produção de práticas de assujeitamento que permeiam o campo de afetações discursivas, que podem ser consideradas como novas práticas de controle e cerceamento subjetivo.

Pensando então em diversidade sexual, identidades e sexualidades dissidentes na formação em Psicologia, devemos articular e estimular problematizações sobre as questões políticas e de poder que configuram essas produções de verdades no tocante a identidades e diferenças (Silva, 2009). Pois é nesse campo relacional de saberes que lidamos com a diversidade de jogos que afetam o discurso psicológico sobre e para o sujeito: "(...) fragmentarismo e mecanicismo $x$ perspectivas mais amplas e integradas; subjetivismo $\mathrm{x}$ objetivismo; mentalismo $x$ materialismo; individualismo $x$ coletivismo; naturalismo biologicista x perspectivas sociais e históricas" (Prado \& Martins, 2007, p. 15).

Sendo assim, tomando como pressuposto a diversidade de jogos teórico-metodológicos que agenciam os discursos psicológicos dentro de um contexto histórico do surgimento, apropriação e desenvolvimento dessa ciência, torna-se cada vez mais necessária a possibilidade de uma inserção nos campos dos saberes de uma Pedagogia da diferença, que agenciem espaços nas rotinas pedagógicas e curriculares não mais em territórios distantes e superficiais sobre as identidades e diferenças, mas estimulem problematizações sobre as questões políticas e de poder que configuram essas produções de verdades no tocante a identidades e diferenças (Silva, 2009).

Essa pertinência se faz por contemporaneamente estarmos experenciando deslocamentos territoriais do desejo e, ao mesmo tempo, sua captura pelos modos de subjetivação e por políticas identitárias.

Conforme argumenta Gayle Rubin (1993 citada Spargo 2006) sobre sexualidade:

O reino da sexualidade tem sua própria política, iniqüidades e modos de opressão internos. Assim como outros aspectos do comportamento humano, as formas institucionais concretas da sexualidade, em qualquer tempo e local, são produtos da atividade humana. Elas estão imbuídas de conflitos de interesse e manobras políticas, tanto deliberados quanto causais. Nesse sentido, o sexo é sempre político. Mas existem também períodos históricos em que a sexualidade é mais acirradamente contestada e mais abertamente politizada. Em tais períodos, o domínio da vida erótica é, com efeito, renegociado (Rubin 1993 citada por Spargo, 2006, p. 6)

Entendemos que, se a sexualidade e sua experienciação são de ordem política de relações, a Psicologia, tendo como primazia a atenção 
ao sujeito, também precisa se voltar às questões políticas de agenciamento dos desejos, do corpo e da própria sexualidade do sujeito. Pois pensando nesse contexto, "(...) estes não são dilemas do sujeito, mas sim de uma cultura e de uma sociedade que polariza qualidades que se ancoram nos corpos dos sujeitos" (Prado \& Martins, 2007, p.18).

Essa citação refere-se à certa política da subjetividade contemporânea, na qual uma das modalidades de renegociação do desejo e da sexualidade parte do pressuposto de como entendemos e agenciamos esses saberes sobre o sexo. É notório que, epistemologicamente até meados do século XIX a sexualidade foi considerada um aspecto natural da vida humana, sendo foco de repressão e proibições pela sociedade e cultura ocidental. Desse modo, estratégias de controle e normatização da sexualidade tornaram-se carro-chefe dentro da sociedade, que tinha como maior agenciador as técnicas e procedimentos psicológicos.

Com os deslocamentos subjetivos da sexualidade e novas possibilidades de experienciação do desejo, não somente no campo da Psicologia, mas em diversas ciências, tem havido discussões e problematizações sobre tais questões, como preconizava Foucault em seus estudos, não tendo sua preocupação voltada para o que é "sexualidade", mas para examinar sua produção, sua funcionalidade e como ela é agenciada na sociedade (Spargo, 2006).

Com efeito, a Psicologia nesse contexto precisa ser vista como possibilidade e saberes de resistência aos processos de assujeitamento e sujeição, no tocante à diversidade sexual, identidades e sexualidades dissidentes.

Cumpre assinalar que, a partir de tais reflexões a Psicologia como ciência, área de atuação e produções de saberes, começou a revisar e reavaliar sua prática dentro de um contexto epistemológico de formação, em uma busca de ampliação e constituição de práticas e saberes que abarcassem o sujeito em situações reais, engendrados por redes comunitárias, sociodinâmicas e institucionais. Isso de certa forma demanda tanto do profissional como do processo de formação em Psicologia,
“(...) ampliar seu arcabouço teórico, revisar conceitos e, principalmente, romper com a noção de sujeito enquanto uma entidade liberal, autônoma, imanente, independente da cultura" (Perez \& Moura, 1999, p. 14).

\section{Construção e reconstrução de referenciais na formação psi}

A partir de produções acadêmicas sobre a falta de identidade profissional, a implementação da Lei de Diretrizes e Bases da Educação Nacional - Lei $n^{\circ}$ 9.394/96 e da implementação dos princípios do Sistema Único de Saúde (SUS), foram agenciadas as transformações na formação dos profissionais vinculados ao SUS, incluindo, nesse cenário, os psicólogos. Para Jorge (2005 citado por MeloSilva et al):

Foram aspectos como desequilíbrio entre a oferta e a demanda do trabalho, a defasagem entre os conteúdos e objetivos do currículo em função das transformações pelas quais foram passando o mundo e a cultura dos indivíduos que chegamos aos dois grandes pressupostos que delinearam nosso projeto de inovação: é preciso modificar o currículo do curso de Psicologia, à luz das necessidades da população que utiliza/necessita dos serviços da Psicologia, há outra esfera de saber que o psicólogo deve dominar (2005, p.80)

As Diretrizes Curriculares dos cursos de Psicologia foram arduamente discutidas e problematizadas pelas diversas instâncias envolvidas na formação profissional (CNE, CFP, IEs, ABEP entre outras). As primeiras diretrizes foram homologadas em 08 de abril de 2004, na gestão do então ministro da Educação, Tarso Genro, e publicadas em Diário Oficial da União (D.O.U.) no dia 12 de abril de 2004. Em 15 de março de 2011, uma nova Diretriz Curricular foi homologada pelo Ministério da Educação-MEC, prevendo agora um projeto complementar para formação em licenciatura. Essa complementação visa ampliar o espelho da formação do psicólogo.

As diretrizes demarcam mudanças nos paradigmas de formação, para Ancona-Lopes (2005): 
A definição do profissional que o curso pretende formar implica em esclarecer a ideologia do curso. É conhecida a acusação de que o currículo mínimo obrigatório privilegia a formação clínica, compreendida como uma abordagem individualista e patologizante, desenvolvida em uma perspectiva que desconsidera o contexto social enquanto constituinte da pessoa. Um posicionamento que valorize a "compreensão crítica dos fenômenos sociais, econômicos, culturais e políticos do País, fundamentais ao exercício de cidadania e da profissão" (Ancona-Lopes, 2005 citado por Melo-Silva et al. 2005, p.95)

É nesse contexto que, para Perez e Moura (1999), o sujeito assume um caráter flexível, plástico, dinâmico dentro de uma existência e funcionalidade agenciada em um território social e cultural, atravessado por "desígnios" que por vezes o capturam e o assujeitam em um processo de engendramento de significações subjetivas. É desse campo/território que emerge, então, um sujeito concreto afetado nas relações que, por sua vez, são permeadas por paradoxos, contradições, ambiguidades e hesitações, não mais apartadas de seu contexto epistemológico.

Assegura então o autor que é nesse campo relacional que surge o objeto da Psicologia, em que esses atravessamentos de dispositivos subjetivos deixam de ser considerados patológicos ou anormais e passam a ser vistos como possibilidades existenciais, impondo de certa forma à ciência psicológica uma revisão de conceitos a respeito do próprio sujeito, da concepção de saúde mental, do conceito de normalidade e, por conseguinte, também das suas práticas na formação em Psicologia.

Como se há de verificar, tais mudanças oportunizaram novas possibilidades de produção de conhecimento partindo de referenciais mais abrangentes das demandas sociais que até então não eram tão discutidas dentro da graduação e formação do profissional, ou vistas apenas a partir de um único referencial. Como compara Bettoi e Simão (2000), diversos estudos e pesquisas consideram pertinentes as necessidades de se refletir sobre a relação entre as “(...) as necessidades sociais, a imagem da profissão, a formação e a atuação profissional" (p.21).
Conforme ratifica Miskolci e Simões (2007), os embates e problematizações no tocante as sexualidades e gêneros nos levam ao enfrentamento, ao confronto e muitas vezes à resistência advinda de paradigmas construídos epistemologicamente por receio de uma suposta degeneração do que já está estabelecido e naturalizado. Desse modo, as grades curriculares embasadas em sua matriz, que oferece as temáticas aqui mencionadas, não somente apresentam um campo teórico de conhecimento, mas direta ou indiretamente inferem na produção de subjetividade de um coletivo que traz consigo o engendramento de discursos sociais advindos de instituições como a família, a igreja, a escola e o campo de trabalho.

É preciso insistir também no fato de que contemporaneamente o modo de subjetivação do sujeito moderno, conforme Cardoso (2005, p. 347) “(...) não pode ser caracterizado como uma moral de código, no sentido prescritivo ou jurídico, que vigia em uma moral cristã". Pois de acordo com Foucault (1985), existe uma orientação da subjetivação para com a relação entre o prazer e a verdade, ou seja, os agenciamentos do poder/saber demarcam territórios subjetivos do que é verdade sobre o sexo para o sujeito moderno. Cabe, ainda, observar que,

O modo de subjetivação moderno, portanto, pode ser surpreendidas em práticas de si reguladas por um dispositivo disciplinar, onde emerge a noção de sexualidade como constitutiva da subjetividade moderna. Sendo assim, a sexualidade, como modo de subjetivação, articula-se com a questão da relação entre o corpo-prazer (transformacional ou criativo) e a verdade sobre o sexo (Cardoso, 2005, p. 347)

Candiotto (2008), ao utilizar-se da teoria foucaultiana, mostra que a relação entre o atravessamento do modo de subjetivação contemporâneo e a produção de discursos/saberes se dá pelos enunciados de verdades culturais agenciadas ao sujeito sobre si mesmo e sobre a realidade, e que por meio da sua funcionalidade circulam, capturam e demarcam espaços subjetivos como verdades absolutas e hegemônicas.

Pensar, então, na formação em Psicologia demanda não mais desassociarmos a produ- 
ção de subjetividade e seus agenciamentos dos dispositivos relacionais que emergem das práticas, das implicações políticas, dos saberes e das dimensões simbólicas constituintes do sujeito, como considera Guareschi e Dhein (2009, p. 68) os quais acreditam que essa concepção de sujeito nos "(...) permite pensar em outros campos de saber, nos discursos como práticos sociais, na promoção destes discursos como aqueles que produzem os sujeitos, nas práticas de significação que constituem os modos de vida".

Essas reflexões, de certo modo, trazem incômodos e desconfortos devido a toda contextualização histórica da ciência psicológica, mas ao mesmo tempo se faz pertinente, pois pensar na formação dentro das academias a partir das suas Matrizes Curriculares e de seus Projetos Pedagógicos (grifo nosso), em uma concepção das implicações culturais e políticas, é pensar nos agenciamentos e atravessamentos discursivos sobre saberes/verdades na formação e práticas psicológicas que acabam sendo dispositivos de força na produção e reafirmação da subjetividade (Guareschi \& Dhein, 2009).

\section{Discursos sobre gênero na formação profissional}

Considerando os referencias teóricos abordados para a problematização deste mapeamento, pode-se pensar em um engendramento de agenciamentos discursivos na formação em Psicologia produzindo saberes/verdades que atravessam as questões relacionadas a gênero, diversidade sexual e sexualidades dissidentes. Sendo que tais atravessamentos se dão a partir de enunciados epistemológicos sobre essas temáticas, demarcando, desse modo territórios subjetivos de desejo, de experimentação do corpo e da própria identidade.

Baseando-nos no procedimento cartográfico e de uma análise genealógica e crítica dos discursos enunciados nas entrevistas realizadas ${ }^{2}$, visualizamos fragmentos da produção discursiva sobre gênero em suas vertentes na formação em Psicologia atualmente.
Partindo desses pressupostos, foram delimitadas três categorias de análise, que se configuram em: 1) Discursos sobre gênero; 2) Saberes e gênero; 3) Desconstrução do gênero identitário.

Como se há de verificar, os discursos na sua materialidade têm sua funcionalidade social/cultural, seja mediante interdições ou produções de verdades/saberes que demarcam territórios de existência, as quais abordaremos nas próximas categorias de análise.

\section{Discursos sobre gênero}

Ao pensarmos nos discursos produzidos pelos acadêmicos de Psicologia e nas divergências que existem entre eles, fica evidente o agenciamento dos atravessamentos desse controle, da seleção e da organização ao qual Foucault (1996) nos fala. Isto porque esclarece o autor que essa tal divergência no campo do discurso se configura devido às interdições que o atravessam por uma ligação com o desejo e o poder ao qual se pretende apoderar-se.

Nessa conformidade, os enunciados que emergem dos discursos dos acadêmicos que entram para formação em Psicologia, tanto em uma universidade pública como em uma universidade privada, remete a uma contextualização não "categorizada" em um referencial teórico psicológico, mas ao que a sociedade contemporânea seleciona, categoriza e apresenta culturalmente, como se pode perceber nas seguintes falas:

"Hoje se tem mais acesso pela mídia que dá uma noção do que se refere sobre gênero e diversidade sexual, mas ainda não está bem claro, pois antes a sociedade era muito rígida, mas hoje ainda é um pouco camuflado." (Acadêmica do $1^{\circ}$ ano - Universidade Pública).

"Tenho apenas uma noção sobre gênero, conheço o que é vinculado à mídia, mas do que se trata sobre sexualidades dissidentes não sei, pois não se fala muito sobre isso apesar da amplitude que tem se mostrado socialmente sobre essas questões" (Acadêmico do $1^{\circ}$ ano - Universidade Privada). 
De certo modo, percebe-se uma ampliação de conceitos e do próprio olhar sobre o sujeito na questão a gênero, diversidade sexual e sexualidades dissidentes, mas ao mesmo tempo como ratifica o autor supracitado: "Existem, evidentemente, muitos outros procedimentos de controle e de delimitação do discurso" (Foucault, 1996, p. 21).

Por outro lado, ao analisarmos os enunciados dos discursos dos acadêmicos que estão se formando em Psicologia, a força de suas falas emerge de outra vertente de seleção e organização discursiva, a qual Foucault (1996) apresenta com relevância ao pensarmos na "função do autor" (p. 29). Nos discursos dos acadêmicos do quinto ano de Psicologia, percebe-se uma suposta necessidade de responder às questões relacionadas a tais temáticas, de um lugar específico, ou seja, pautado sobre referenciais teórico-metodológicos da Psicologia.

"É discutido desde o início dentro da Psicologia Social e Institucional, onde trabalha a educação sexual. Com a formação mudou muito a concepção que tinha antes sobre o assunto, agora é mais pertinente essa temática" (Acadêmica do $5^{\circ}$ ano - Universidade Pública).

"Segundo Simone de Beauvoir é uma construção social e cultural. O sujeito se faz enquanto gênero" (Acadêmica do $5^{\circ}$ ano Universidade Privada).

Verificam-se, nas falas acima descritas, discursos cerceados por saberes institucionalizados que podem agenciar na sua atuação demarcações de territórios subjetivos teorizados ou patológicos, ou propiciar novos espaços de experimentação e de possibilidades ao sujeito, no tocante ao gênero e suas nuances. Assim, os discursos partem da função que esse autor-acadêmico tem ou pretende ter em um contexto social e cultural, ou seja, nas interdições e demarcações subjetivo-discursivas de um recorte de diferentes prismas de visão de mundo e de homem. Pois "este jogo de diferenças é prescrito pela função do autor, tal como a recebe de sua época ou tal como ele, por sua vez, a modifica" (Foucault, 1996, p. 29).
Nesse sentido, ao analisarmos os enunciados discursivos e suas divergências, entre os acadêmicos que entram na formação em Psicologia e os que se formam independentemente da universidade ser pública ou privada, o atravessamento de referenciais que são postos em um agenciamento rizomático na circulação desses discursos demarca territórios subjetivos a partir de um suposto saber sobre gênero, diversidade sexual e sexualidades dissidentes.

Nessa perspectiva podemos dizer que ao mesmo tempo em que na atualidade apesar de aparentemente apresentar uma visibilidade maior e uma problematização sobre tais temáticas, seja em um contexto midiático social/cultural amplo ou dentro da academia, ainda existe uma necessidade de demarcação de territórios subjetivos, ao qual segundo contribuições da Teoria Queer essa materialidade do gênero, da sexualidade e do próprio desejo se dá a partir de renegociações da vida erótica e das formas que socialmente entendemos o sexo (Spargo, 2006).

No que tange à formação em Psicologia, os discursos pautados no contexto de gênero, diversidade sexual e sexualidades dissidentes, apresenta-se com força em um processo de desconstrução e construção de saberes/verdades que o acadêmico tem sobre o assunto, dentro de uma diversidade de jogos que agenciam os discursos psicológicos (Prado \& Martins, 2007).

\section{Saberes e Gênero}

Pelo exposto, os discursos na sua materialidade têm sua funcionalidade social/cultural agenciados em enunciados de interdições e em produções de verdades/saberes que demarcam territórios subjetivos de desejo, de sexualidade e de experimentação do corpo. Nesse compasso, a partir da análise dos discursos sobre gênero na formação em Psicologia, nas falas dos sujeitos ali inseridos, constata-se tal atravessamento, seja a partir de um contexto epistemológico, cultural, metodológico-teórico ou midiático. 
Diante dessa constatação, é pertinente pensarmos e analisarmos as forças desses dispositivos de saberes que atravessam o campo relacional e subjetivo do sujeito no processo de formação em Psicologia, para tentar entender os efeitos de subjetivação na sua processualidade e funcionalidade discursiva.

Nessa conformidade é interessante pensarmos no desvelamento de Foucault (1996) sobre os discursos e os agenciamentos de saberes/verdades os quais atravessam e os compõem, pois para o autor é em meados do século XIX que emerge na sociedade a necessidade, ou melhor, "uma vontade de verdade" (p.16), modificando dessa forma todo o contexto social da época, que até então era somente articulado e referendado sobre "(...) o discurso pronunciado por quem de direito e conforme o ritual requerido" ( $p$. 15); principalmente no tocante às questões consideradas mais inquietantes para a norma e moral social, como a loucura e a sexualidade.

Tanto é assim que, nesse momento os discursos passam a ser agenciados por meio de procedimentos de controle e de delimitação, apoiando-se agora em um suporte institucional que reconduz tais discursos a partir de "(...) um saber que é aplicado em uma sociedade, como é valorizado, distribuído, repartido e de certo modo atribuído" (p.17).

No que diz respeito, então, às questões de gênero, diversidade sexual e sexualidades dissidentes, a produção discursiva se dá a partir de enunciados produzidos referentes ao sexo, ao corpo e à moral social. Para tanto, pensar em formação em Psicologia dentro desse contexto é cartografarmos os saberes/verdades que emergem sobre o sexo e subjetividade, bem como os efeitos produzidos a partir dos seus agenciamentos. Pensando nesse prisma, a evidência dos fatos se dá nas falas dos entrevistados que ratificam o assunto:

"O humano é um sujeito mutável, mas não tão livre assim, onde o ego é a maneira de lidar com a vida, sendo o gênero uma expressão da pessoa". (Acadêmica do $5^{\circ}$ ano Universidade Privada).
"O ser humano depende da visão de homem de cada um". (Acadêmica do $5^{\circ}$ ano - Universidade Pública).

"O ser humano está vivendo só no externo, numa época de transição com mais escolhas para fazer sobre sexualidade, mas que ainda são limitadas". (Acadêmico do $1^{\circ}$ ano - Universidade Particular).

"O ser humano é completo, onde seu desejo é plástico/flexível, mas controlado pelas normas". (Acadêmico do $1^{\circ}$ ano - Universidade Particular).

Desse modo verifica-se que os saberes articulados e postos sejam no âmbito do senso comum ou de cunho científico, engendram os discursos sobre tais temáticas emergindo efeitos de força não somente na produção de subjetividade, mas também na demarcação de territórios de desejo, de experimentação e de subjetivação. Isso se dá por indivíduo ser considerado:

(...) portanto, o alvo desse esquadrinhamento histórico. Esquadrinhamento se refere ao conjunto de práticas políticas e sociais: são as disciplinas, os exames, as vigilâncias, por exemplo. Todas elas responsáveis por instaurar uma fina película reguladora das estratégias de poder (Soler, 2008, p. 575)

Esses dispositivos de força se configuram de maneira mais intensa quando se tratam de questões como a sexualidade e suas vertentes, que indireta ou diretamente, têm grande pertinência no contexto da moral social no seu processo epistemológico. Na atualidade, esses pressupostos são evidenciados e problematizados com mais afinco a partir de uma visão queer na qual se busca uma desconstrução do binarismo hegemônico que é predominante no que diz respeito à produção de saberes/verdades sobre gênero, diversidade sexual e sexualidades dissidentes.

Torna-se relevante, pensando na formação em Psicologia e nos saberes engendrados nesse processo, que a Psicologia como ciência surge em um momento histórico no qual o contexto social se configura em relação à sexualidade e sua diversidade, em um campo relacional de conflitos intensos, devido à 
existência de um "(...) discurso sobre a 'verdade' do sexo" (Teixeira, 2011, p. 57). De certo modo isso demarca o que se entende sobre sexualidade e a partir daí a normatização de dispositivos que a reafirmem, a categorize e a faça circular dentro de padrões estabelecidos pela norma social predominante, a qual Foucault (1979) vai delinear como uma processualidade e funcionalidade do biopoder e da biopolítica sobre o corpo, sobre a subjetividade e sobre o desejo.

\section{Desconstrução do Gênero Identitário}

Como referendado nas categorias anteriores, o discurso sobre gênero, diversidade sexual e sexualidades dissidentes é engendrado em um agenciamento de saberes/verdades na sua materialidade e na sua circulação, sendo que esses saberes/verdades estão pautados e produzidos em redes de interdições, de normas morais e de uma suposta "verdade" sobre o sexo. Por isso, muito se tem discutido, recentemente, acerca de gênero e identidade se configurando, de certo modo, uma demanda social ao ser olhada e pensada também no campo psicológico.

Para tanto, problematizar sobre subjetividade em todo o seu contexto na formação em Psicologia, dentro das demandas que emergem constantemente na sociedade, fez pensar e discutir novas propostas metodológicas e práticas estabelecidas pelas Diretrizes Curriculares. Essa realidade conforme Perez e Moura (1999), acontece devido à busca de uma formação generalista que propicie aos que adentram a formação um comprometimento maior com as questões sociais, sendo considerados agentes de transformação nesse processo de afetos e afetação.

Apesar de muitas divergências a respeito de tais propostas de mudança, tem ocorrido de certo modo, segundo os autores supracitados, uma ruptura com alguns modelos e práticas em um âmbito ainda biomédico, possibilitando por meio de uma bricolagem de conhecimentos a "(...) possibilidade da Psicologia vir a constituir um saber e uma prática capaz de apreender o ser humano em suas situações concretas, nos âmbitos sócio-dinâmico, institucionais e comunitário" (Silva, 1992 citado por Perez \& Moura, 1999, p.13).

Não é mansa e pacífica a questão, como percebido nos enunciados dos entrevistados que apresentam divergências no seu contexto, a partir de afetações de discursos/saberes que delimitam, ou até mesmo categorizam o desejo, a experimentação, a identidade e a diferença. Assim, é pertinente trazermos para a análise essa bricolagem de conhecimentos que atualmente vem problematizando e contribuindo para pensarmos no gênero, diversidade sexual e sexualidades dissidentes em Psicologia.

Partindo do entendimento foucaultiano sobre sexo e seu agenciamento pelo biopoder e pela biopolítica, pensar então em gênero segundo Porchat (2011) é analisar que o conceito de identidade de gênero ou gênero “(...) agrupa aspectos psicológicos, sociais, históricos, culturais, associados à feminilidade e à masculinidade por oposição ao sexo que designaria os componentes biológicos e anatômicos" (p.46). É de verificar-se, então, que algumas teorias trazem e problematizam a desconstrução de um gênero identitário, que ainda é circulado discursivamente nos saberes/verdades sobre tal temática.

Resulta claramente, dentro desses parâmetros, que se tratando de identidades, seja também no seu contexto sexual afirma Woodward (2009):

As identidades são fabricadas por meio da marcação da diferença. Essa marcação da diferença ocorre tanto por meio de sistemas simbólicos de representação quanto por meio de formas de exclusão social. A identidade, pois, não é o oposto da diferença: a identidade depende da diferença. Nas relações sociais, essas formas de diferença - a simbólica e a social - são estabelecidas, ao menos em parte, por meio de sistemas classificatórios ( pp. 39-40)

Deste modo, retomando o relato dos entrevistados descritos nas categorias anteriores de análise, dá para pensarmos que os discursos/saberes sobre a identidade subjetiva 
do desejo e da experimentação do corpo acabam afetados por esse sistema classificatório da diferença, dentro de um contexto binário e hegemônico da sexualidade articulado social e culturalmente nas relações (Silva, 2009). De fato que nessa processualidade binária de classificação do gênero, do sexo, da identidade e da diferença, é que a Psicologia durante muito tempo acabou respondendo e dando vazão aos seus estudos e produções de saberes, até mesmo devido ao contexto epistemológico ao qual se encontrava e do que a própria ciência entendia como subjetividade (Guareschi \& Dhein, 2009).

A contribuição da Teoria Queer e dos Estudos Culturais tem possibilitado a discussão e a problematização no campo psicológico como em tantos outros, sobre a desconstrução de políticas identitárias de gênero, que demarcam territórios de existências e uma visão classificatória do sujeito a partir de sua diferença. Pois dentro de uma visão dos teóricos queer:

(...) gênero vai agrupar anatomia, identidade de gênero, desejo e prática sexual. Esses quatro itens supostamente guardariam coerência entre si, principalmente para um observador externo, ou seja, quando olhamos alguém, costumamos ver e esperar uma coerência de gênero nessa pessoa. Mas, do ponto de vista do sujeito em si, nem sempre acontece (Porchat, 2011, p. 43)

Por isso dentro desse contexto de desconstrução identitária do gênero cujo engendra e agencia a diversidade sexual e sexualidades dissidentes, Teixeira (2011) apresenta para os profissionais e pensadores da Psicologia contemporânea, que é o momento oportuno onde à subjetividade tem se configurado em outras instâncias e a sexualidade heteronormativa tem se questionado, no qual se deve no campo psicológico agregar saberes/verdades que não produzam discursos/verdades classificatórios, mas possibilitem campos de resistências e amplitude não de verdades fixas, mas de experimentações existenciais numa plasticidade subjetiva de afetos e afetações.

\section{Considerações Finais}

De acordo com a argumentação desenvolvida neste artigo, podemos perceber num primeiro momento o atravessamento de discursos/saberes que agenciam não somente o campo de conhecimento, mas as próprias concepções sobre o sujeito e suas relações. A afetação engendrada no contexto relacional no tocante a gênero, diversidade sexual e sexualidades dissidentes são articuladas e pautadas epistemologicamente sobre uma suposta "verdade" sobre o sexo no âmbito da moral social de classificação da identidade e da diferença a partir da demarcação de um modelo binário e hegemônico.

Atualmente, alguns teóricos têm trazido em pauta para essa discussão sobre gênero a necessidade da desconstrução identitária que demarca territórios de desejo, de experimentação e de subjetivação. Dentre eles, se encontram teóricos da Teoria Queer e dos Estudos Culturais que vem contribuindo de maneira significativa, quando se pensa numa análise e problematização de tais temáticas.

É neste cenário onde se é discutido questões relevantes sobre o gênero, diversidade sexual e sexualidade dissidentes, que a Psicologia como uma das ciências que tem a subjetividade como fonte de estudo, vem se reavaliando teórica-metodológicamente nas suas práticas psi, além dos discursos/saberes agenciados na sua formação. Para tanto, mediante a pesquisa realizada com acadêmicos de universidade pública e privada, a partir de sua entrada na formação em Psicologia, bem como na sua saída, percebe-se a divergência de discursos/saberes entre os mesmos.

Assim, a força que emerge como dispositivo de força nos enunciados dos entrevistados configura a partir da sua materialidade um atravessamento de saberes/verdades que se dão a partir da formação em Psicologia, além do atravessamento discursivo de articulações de verdades sociais e culturalmente agenciados e vinculados nas relações. É um processo de construção e reconstrução constante, que objetiva de acordo com Peres (2011) a: 
(...) emancipação psicossocial e cultural das pessoas, sem classificação, sem patologização e sem reducionismos teóricos, rompendo de vez com paradigmas binários, universais e essencialistas de manutenção ao sistema sexo/gênero/desejo que tanto impede o direito de $\operatorname{ser}(\ldots)($ p. 104)

Deste modo, a partir da implementação de Diretrizes Curriculares a formação em Psicologia tem agregado ao seu campo uma bricolagem de conhecimento que favorece o questionar-se a partir de outras vertentes que de forma alguma delimita, mas ao contrário abre possibilidades de olhar e acolher as novas demandas sociais.

Isso não quer dizer que ao se pensar nas produções discursivas e na produção de saberes/verdades sobre gênero, diversidade sexual e sexualidades dissidentes na formação em Psicologia não temos que pensar e repensar nesse agenciamento de enunciados que podem ainda demarcar territórios subjetivos de experimentação, desejo, identidade e diferença

\section{Rogério Amador de Melo}

Mestrando em Psicologia e Sociedade/UNESP-Assis-SP. Psicólogo.

Rua Jandaia 5037, Centro - Cep: 87.502-130. Umuarama - Paraná.

Telefone: (44) 9914-8366. Email: melo_rogers@yahoo.com.br .

\section{Danielle Jardim Barreto}

Doutoranda em Psicologia e Sociedade/UNESP-Assis-SP;

Docente do Curso de Psicologia da

Universidade Paranaense - UNIPAR/Umuarama-Pr.

Universidade Paranaense - Apec, Sede.

Email: psicologia-umu@unipar.br.

Endereço para envio de correspondência:

Rua Jandaia 5037, Centro. CEP: 87.502-130. Umuarama - PR. Brasil

Recebido 31/05/2012, 1aㅡ Reformulação 22/04/2013, Aprovado 29/08/2013. 


\section{Referências}

Bettoi, W.; \& Simão, L.M. (2000). Profissionais para si ou para outros? Psicol. cienc. Prof, 20(2), 20-31. doi: 10.1590/S141498932000000200005.

Diáz-Benitez, M.E., \& Figari, C.E. (2009). Prazeres Dissidentes. Rio de Janeiro: Garamond.

Candiotto, C. (2008). Subjetividade e Verdade no Último Foucault. Trans/Form/Ação, São Paulo, 31(1), 87-103. doi: 10.1590/S010131732008000100005

Cardoso, H.R.Jr. (2005). Para que serve uma subjetividade? Foucault, Tempo e Corpo. Psicologia: Reflexão e Crítica, 18(3), 343-349. doi: 10.1590/S0102-79722005000300008

Ceccin, R. B.; \& Pinheiro, R. (Orgs). (2005). Ensinar Saúde: a integralidade e o SUS nos cursos de graduação na área da saúde. Rio de Janeiro: IMS/UERJ: CEPESQ: ABRASCO.

Foucault, M. (1979). Microfisica do Poder. Rio de Janeiro: Graal.

Foucault, M. (1984). História da sexualidade 2: o uso dos prazeres. Rio de Janeiro: Graal.

Foucault, M. (1985). História da sexualidade 1: a vontade de saber. Rio de Janeiro: Graal.

Foucault, M. (1996). A ordem do discurso. São Paulo: Loyola.

Guareschi, N. M. F.; \& Dhein, G. (2009). Formação em Psicologia: história, cultura e política. In D. Tatsch; N. M. F. Guareschi \& S.T. Baumkarten (Orgs.). Tecendo Relações e Intervenções em Psicologia Sócia. (Vol. 1, pp. 64-73). Porto Alegre: ABRAPSO SUL

Melo-Silva, L.L. et al. (2005). A inovação curricular: Bases teóricas e metodológicas para a implementação de mudanças nas práticas da Psicologia. In L.L., Melo-Silva, M. A., Santos, \& C. P. Simon, et al. Formação em Psicologia: serviços-escola em debate. (pp. 221-226). São Paulo: Vetor.

Miskolci, R.; \& Simões, J.A. (2007, jan./jun). Quereres. Cadernos Pagu. Campinas, 28. Rio de Janeiro: Nova Fronteira.
Peres, W.S. (2011). Tecnologias e programação de sexo e gênero: apontamentos para uma Psicologia política QUEER. In Conselho Federal de Psicologia. Psicologia e Diversidade Sexual: desafios para uma sociedade de direitos. Brasília, DF: Autor.

Perez, E.; \& Moura, G. (1999). A Psicologia (e os Psicólogos) que temo e a Psicologia que queremos: reflexões a partir das propostas de Diretrizes Curriculares (MEC/SESU) para os Cursos de Graduação em Psicologia. Psicol. cienc. Prof., 19(2) 10-19. doi: 10.1590/S141498931999000200003

Porchat, P. (2011). A noção de gênero como operadora conceitual na clínica psicológica. In Conselho Federal de Psicologia. Psicologia e Diversidade Sexual: desafios para uma sociedade de direitos. Brasília, DF: Autor.

Prado, K. Filho.; \& Martins, S. (2007). A subjetividade como objeto da(s) Psicologia(s). Psicologia \& Sociedade. 19(3), 14-19. doi: 10.1590/S0102-71822007000300003.

Serres, M. (1993). Filosofia Mestiça: Le tiersisntruit. Rio de Janeiro: Nova Fronteira.

Silva, T. T. (2009). A produção social da identidade e da diferença. In T. T. Silva; S. Hall \& K. Woodward. (2009). Identidade e diferença: a perspectiva dos estudos culturais (9a. ed.). Rio de Janeiro: Vozes.

Soler, R.D.V. (2008). Uma história política da subjetividade em Michel Foucault. Fractal: Revista de Psicologia, 20(2), 571-582. doi: 10.1590/S1984-02922008000200019

Spargo, T. (2006). Foucault e a teoria queer. (Vladimir Freire, trad.) Rio de Janeiro: Ed. UFJF.

Teixeira, F.S. Filho. (2011). Apontamentos para uma Psicologia contra-homofóbica. In Conselho Federal de Psicologia. Psicologia e Diversidade Sexual: desafios para uma sociedade de direitos. Brasília, DF: Autor.

Woodward, K. (2009) Identidade e diferença: uma introdução teórica e conceitual. In T. T., Silva, S., Hall, \& K. Woodward. Identidade e diferença: a perspectiva dos estudos culturais (9a. ed.). Rio de Janeiro: Vozes. 